\title{
Deferring sternal closure after complex congenital heart surgery-to do or not to do is the question!
}

\author{
Krishna Subramony lyer $^{1}$ (D) \\ Received: 1 March 2019 / Revised: 11 March 2019 / Accepted: 19 March 2019 / Published online: 24 May 2019 \\ (C) Indian Association of Cardiovascular-Thoracic Surgeons 2019
}

Delayed or deferred sternal closure (DSC) has for many years been an established modality for reducing post-operative morbidity and mortality in congenital heart surgery. It has been particularly utilized following complex repairs in neonates and infants, especially when prolonged cardio-pulmonary bypass has been involved. DSC reduces external compression on a heart that may be dilated from ventricular dysfunction, volume loading, or myocardial edema, thereby improving cardiac output $[1,2]$ and was probably first described for this indication by Gangahar et al. in 1981 [3]. It also allows for higher ventilator pressures to be used when lung compliance is reduced without adversely affecting ventricular filling. Additionally, in the event of inadequate intra-operative hemostasis, an open sternum averts cardiac tamponade and also allows for faster institution of extra-corporeal mechanical support, should the need arise. DSC, on the other hand, potentially prolongs duration of mechanical ventilation and intensive care unit and hospital stay. Increased sternal wound infection or systemic sepsis has been reported by some [4, 5], while others do not feel that DSC is associated with increase in mediastinal infection. Shin et al. [6] opine that the increased rates of infection are related more to additional ventilator times required, rather than DSC in itself.

Given that deferred sternal closure has become an established surgical care practice in congenital heart surgery, it will not be ethical today to do a double-blind study to prove its efficacy. The extent of its use is highly variable depending on individual beliefs and institutional policies [7]. Many surgeons would make an on table decision, on a case to case basis, while others would defer sternal closure as a routine in certain select surgical procedures, irrespective of the hemodynamic status at the end of surgery. Often times, these decisions

Krishna Subramony Iyer iyerks@hotmail.com

1 Pediatric and Congenital Heart Surgery, Fortis Escorts Heart Institute, Okhla Road, New Delhi 110025, India are tempered by the unit's comfort level with deferred sternal closure and their own perception of benefits versus complications. A recent study by Ram Kumar et al. [8] analyzed 1000 patients, mostly newborns, who had deferred sternal closure following complex congenital heart repairs. They had a liberal approach to deferring sternal closure, utilizing it almost uniformly for all operations performed under circulatory arrest, or those in Society of Thoracic Surgeons-European Association for Cardio-Thoracic Surgery (STAT) category 4 or 5. They concluded that a liberal policy of DSC does not adversely affect surgical outcomes, including infectious complications and length of stay and that need for DSC should not, by itself, be considered a source of morbidity.

Following DSC, it is generally possible to close the sternum within 2-4 days. Every attempt should be made to close the sternum as soon as the primary indication for DSC has been resolved [9]. The sternum may be closed in the intensive care unit or the operating room, depending on unit preference, unless an intervention is required necessitating return to the operating room. In one study, no difference in infection rates was found between sternal closure in the operating room or elsewhere [4].

In this issue of IJTC, Kundan et al. [10] have analyzed their experience with deferred sternal closure over a 5 -year period that covered 2111 operated patients. They conclude that in patients with doubtful post-operative hemodynamics, the choice of leaving the sternum open has better outcomes than opening the sternum, in the intensive care unit (ICU), as a bail out procedure. They base this conclusion on the finding that the patients who had a deferred sternal closure had a mortality of $11.16 \%$, compared with a mortality of $71.42 \%$ in those who had the sternum opened secondarily in the ICU.

To my mind, the study is basically flawed in that the two groups of patients are totally different subsets and so are not strictly comparable. Patients who had deferred sternal closure were those who were either hemodynamically unstable or expected to have hemodynamic instability in the immediate post-operative period. Patients who had the sternum opened 
in the ICU had presumably stable hemodynamics in the operating room and so had been shifted to the ICU with a closed sternum. This is the stated criterion for sternal closure in the authors' study. So while the first group had an elective proactive intervention, the second group had an emergency rescue procedure. The reason for open sternum in both instances is totally different and so no meaningful comparison should ensue.

The second problem with the data is that it includes patients who had the sternum open for reasons other than hemodynamic instability - mediastinal bleeding and need for mechanical support. Bleeding may not necessarily be associated with hemodynamic instability, and central extra-corporeal membrane oxygenation (ECMO) requires an open sternum in children. Both these groups of patients do not fall into the category of deferred sternal closure for hemodynamic instability.

The only way that the authors could have proved their thesis was by randomizing patients with evident or potential hemodynamic instability into two groups - with or without deferred sternal closure and then analyzed the outcomes. This of course would probably not clear an ethics committee, given the data that is available on the beneficial effects of deferred sternal closure.

The problem with most pre-emptive interventions is that they are either used too liberally or too conservatively, depending on the perceived benefits and disadvantages. Examples of such interventions include siting of temporary pacing wires, intra-operative placement of peritoneal dialysis catheter, placement of left atrial or pulmonary artery catheters in pediatric practice, and institution of an intra-aortic balloon pump in adult patients. In most instances, a pre-emptive intervention is done, based on a subjective assessment of the situation. It may work out right in the majority, but there will be a set of patients who may not behave as predicted and then lose out on the benefit of a pre-emptive intervention that was not done.

This holds true for deferred sternal closure. The decision is taken in the operating room based on an assessment of the expected post-operative course. In the event of hemodynamic deterioration in a patient with a closed sternum, the opportu- nity for pro-active intervention has already been lost, because the event that was to be prevented has already happened. That is why the two groups - deferred closure in the operating room and emergency sternal reopening in the ICU cannot be compared!

\section{References}

1. McElhinney DB, Reddy VM, Johnson LD, Hanley FL. Open sternotomy and delayed closure following cardiac surgery in neonates: outcomes of a strategy for manging critically ill patients. Pediatr Res. 1997:41:36.

2. Tabbutt S, Duncan BW, McLaughlin D, Wessel DL, Jonas RA, Laussen PC. Delayed sternal closure after cardiac operations in a pediatric population. J Thorac Cardiovasc Surg. 1997;113:886-93.

3. Gangahar DM, McGough EC, Synhorst D. Secondary sternal closure: a method of preventing cardiac compression. Ann Thorac Surg. 1981;31:281-2.

4. Nelson-McMillan K, Hornik CP, He X, et al. Delayed sternal closure in infant heart surgery - the importance of where and when: an analysis of the STS congenital heart database. Ann Thorac Surg. 2016;102:1565-72.

5. Das S, Rubio A, Simsic JM, et al. Bloodstream infections increased after delayed sternal closure: cause or coincidence. Ann Thorac Surg. 2011;91:793-7.

6. Shin HJ, Jhang WK, Park JJ, Yun TJ. Impact of delayed sternal closure on postoperative infection or wound dehiscence in patients with congenital heart disease. Ann Thorac Surg. 2011;92:705-9.

7. Johnson JN, Jaggers J, Li S, et al. Center variation and outcomes associated with delayed sternal closure after stage 1 palliation for hypoplastic left heart syndrome. J Thorac Cardiovasc Surg. 2010;139:1205-10.

8. Ram Kumar S, Scott N, Wells WJ, Starnes VA. Liberal use of delayed sternal closure in children is not associated with increased morbidity. Ann Thorac Surg. 2018;106:581-6.

9. Riphagen S, McDougall M, Tibby SM, et al. "Early" delayed sternal closure following pediatric cardiac surgery. Ann Thorac Surg. 2005;80:678-84.

10. Kundan S, Tailor K, Radhakrishnan HB, et al. Elective delayed sternal closure portends better outcomes in congenital heart surgery: a retrospective observational study. Indian J Thorac Cardiovasc Surg. https://doi.org/10.1007/s12055-019-00830-1

Publisher's note Springer Nature remains neutral with regard to jurisdictional claims in published maps and institutional affiliations. 